\title{
IAMJ
}

INTERNATIONAL

AYURVEDIC

MEDICAL JOURNAL

ISSN: 2320-5091

Impact Factor: 6.719

\section{NEW DOSAGE FORM IN AYURVEDA - THERMO-SENSITIVE VAGINAL GEL OF PVK EXTRACT}

\section{$\underline{\text { Kirtidhara Behera }}^{1}$, $\underline{\text { Usha Sharma }}^{2}$, $\underline{\text { Shuchi Mitra }}^{3}$, Khem Chand Sharma ${ }^{4}$}

MD Scholar ${ }^{1}$, Profssor ${ }^{2}$, Associate Professor ${ }^{3}$, Professor $^{4}$

PG Department of Rasa Shastra \& Bhaishjya Kalpana

Uttarakhand Ayurved University, Dehradun, Uttarakhand, India

Corresponding Author: dr.kirtidhara2010@gmail.com

https://doi.org/10.46607/iamj2509082021

(Published Online: August 2021)

Open Access

(C) International Ayurvedic Medical Journal, India 2021

Article Received: 11/07//2021 - Peer Reviewed: 17/07/2021 - Accepted for Publication: 18/07/2021

\section{Check for updates}

\begin{abstract}
Rasashastra \& Bhaisajya Kalpana is the prime branch of Ayurveda because of the preparation of medicine described in this branch. In ancient times pharmacokinetics of the drug was described in the principle of Dosha and Dushya which is a comprehensive matter for Ayurvedic professionals. But for global acceptance, we need to describe this view (pharmacokinetics) in the form of pharmacological language and convert this ancient medicine in the form of new dosage forms like gel, granules, syrup etc. Panchavalkal Kashaya was described for the treatment of women disease wounds and ulcers in different Ayurvedic texts like Charaka Samhita, Sharangdhara Samhita, Kashyapa Samhita, Bharat Bhaisajya Ratnakar, Bhava-Prakash. In this article, an attempt has been made to describe how to prepare the thermo-sensitive vaginal gel form, of Panchavalkal Kashaya extract for the use of women diseases like leucorrhoea. The thermosensitive gel is in the liquid form at room temperature (20$25^{\circ} \mathrm{C}$ ) and undergoes gelation when in contact with body fluid $\left(35-37^{\circ} \mathrm{C}\right)$. There are many thermo-sensitive polymers like cellulose derivatives, poloxamer, poly (ethylene oxide) /poly (D, L- lactic acid-glycolic acid).
\end{abstract}

Keywords: Ayurveda, Panchvalkal Kashaya, Thermo-sensitive gel, Charaka Samhita. 


\section{INTRODUCTION}

In the coming days and at present bacterial and fungal resistant infection has become a global health challenge and threatening the health of society. Due to the resistant infections, existing antibacterial drugs have become less effective. So global acceptance of Ayurvedic medicine is increasing day by day due to its natural way of working according to human physiology and pathology ${ }^{[1]}$ RTI is the major cause of morbidity and mortality in women and neonates. Globally it is estimated that as many as 340 million new cases of curable STD other than HIV/AIDS occurs each year, most of which are occurring in developing countries. The greatest impact of RTI/STI is on women and children. ${ }^{[2]} \mathrm{PVK}$ (Panchavalkal) is one of an acceptable combination of the medicinal group described in all standard Ayurvedic text ${ }^{[3]}$ It is the combination of barks of five medicinal plants namely Vata (Ficus bengalensis, Linn), Udumbara (Ficus racemosa, Linn), Peepal (Ficus religiosa, Linn), Plaksha (Ficus infectoria/Ficus lacer) and Parisha (Thespia populenea), in equal proportions described for the treatment of the women's disease, wound and ulcer in different Ayurvedic text like Charak Samhita, Sarangdhara Samhita, Kasyapa Samhita, Bharat bhashaijya Ratnakar and Bhavaprakasha. ${ }^{[4]}$ Many studies were carried out for the use of vaginal douche of PVK in uncomplicated leucorrhoea. This douche had to be prepared fresh every day and was an exhausting as well as the timeconsuming process for the health assistant as well as a physician. It was also time-consuming, uncomfortable and costly for the patient. Hence there is a great need to develop a vaginal formulation that could be self-administered at home by the patient with proper hygiene ${ }^{[5]}$ In 2013 CCRAS developed a monograph on modified Panchavalkal which consist of Vata, Udumbara, Peepal, Plaksha and Shirish. The study was carried out by Jayashree Joshi, Rama Vaidya, Dr Sujata Jagtap, Vanita Rege, Dr Dillip Mehta, Dr Geeta Varage, on uncomplicated Leucorrhoea revealed that modified PVK with Shirish had the best antibacterial and antifungal activity. In this study, they had developed a vaginal cream from the extract of modified PVK. In case of vaginal infection, the direct application of the cream onto the infected sites by the applicator is very difficult, there is a chance of self-injury, and it is also inconvenient. To overcome this problem in situ gelling liquid doses form have been investigated for vaginal delivery. This liquid when applied to the vaginal cavity turns into a gel as a result of chemical/physical change induced by the physiological environment. In a future study, the scholar will prepare a thermo-sensitive vaginal gel of modified PVK extract for uncomplicated Leucorrhoea. Which will be easy to apply and retain at the biological surface for a longer time and the drug will be released in a controlled manner close to the absorptive membrane, with a consequent enhancement of bioavailability ${ }^{[6]}$ The phytochemicals of PVK proved their antibacterial and antifungal activity which is given below.

Tannin: -The antibacterial activities of tannin are well documented. The growth of many fungi, Yeast, Bacteria, Virus were inhibited by Tanin ${ }^{[7]}$

Rutin:- Rutin is also known as vitamin-P enhance the action of vitamin $\mathrm{C}$. It is used to treat an inflammatory condition ${ }^{[8]}$

Friedelin:- It shows anti-inflammatory activity: ${ }^{[9]}$

Leucoanthocyanin:-It is used for swelling ${ }^{[10]}$

Coumarin:- Coumarin possess a variety of biological properties, including antimicrobial, antiviral, antiinflammatory. ${ }^{[11]}$

Stigmasterol:- Stigmasterol have anti-inflammatory property ${ }^{[12]}$

Lupeol:- Lupeol has been extensively studied for its inhibitory effects on inflammation in vitro and animal models of inflammation. ${ }^{[13]}$

Lupeol acetate:-Lupeol acetate has been reported to have anti-inflammatory, anti-microbial, anti-malarial and anti-tuberculosis activity ${ }^{[14]}$

Taraxasterol ester:-Taraxasterol have antimicrobial, anti-allergic, antioxidative and antiinflammatory activity ${ }^{[15]}$ 
Hentriacontane:- Hentriacontane was shown to ameliorate the expression of inflammatory mediators ${ }^{[16]}$

Scutellarein:- Scutellarein shows the antiviral activity. Sorbitol also show antiviral activity ${ }^{[17]}$

D-catechin:- Anti-inflammatory, anti-proliferative. [18]

Albizziahexoside A:- It shows the analgesic effect ${ }^{[19]}$ Material and Method

In recent years the attention of scientists draws towards the vaginal route of drug delivery due to its unique features including, large surface area, high perfusion rate, the feasibility of uterine drug targeting and good permeability of many drugs. In the thermosensitive vaginal gel before administration in situforming systems are the liquid aqueous solution but convert to gel under physiological conditions. Several possible mechanisms lead to in situ gel formation like UV-irradiation, Ionic cross-linkage, $\mathrm{pH}$ change and temperature modulation. In an article by Dr D.Y Patill "Development of thermosensitive gel of Fluconazole for vaginal candidiasis" The scholar come to know the process and mode of action of thermo-sensitive vaginal gel. In this article, the method of preparation described as the in-situ gelling solution was prepared on a weight basis using the cold method. The required amount of Ps 407 (15$20 \% \mathrm{w} / \mathrm{w})$ was dispersed in water containing benzalkonium chloride $(0.01 \% \mathrm{w} / \mathrm{w})$ and $5 \% \mathrm{w} / \mathrm{w}$ glycerol at $5+3{ }^{\circ} \mathrm{c}$, The partially dissolved P 407 solutions were stored in the refrigerator for 24 hours until the complete dissolution of the polymer. Fluconazole(FCZ 1\% w/w) was dissolved in $10 \%$ w/w propylene glycol. This solution was added dropwise to the P 407 solution and mixed uniformly to obtain the final formula. By this process we can develop the PVK thermo-sensitive vaginal gel This will be the new doses form of ayurvedic formulation PVK (use for gynaecological disease ). By the following step, we can develop the thermo-sensitive vaginal gel of PVK exact.
Extraction is the method by which we can separate the medicinally active portion of plant tissues using selective solvent through standard procedure. The general techniques of medicinal plant extraction are

1) Maceration

2) Infusion

3) Percolation

4) Digestion

5) Decoction

6) Hot continuous extraction(Soxhlet)

7) Aqueous-alcoholic extraction by fermentation

8) Counter-current extraction

9) Microwave-assisted extraction

10) Ultrasound extraction (Sonication)

11) Supercritical fluid extraction

12) Phytonic extraction (with hydroflurocarban solvant)

In that method, the scholar will select the Hot continuous extraction (Soxhlet) method for the extraction of Panchavalkal. First of all the scholar will collect the crude drugs according to the procedure. Then clean it and dry it properly. After that, the scholar will cut the drugs into small pieces. Then grind it in a pulverizer. This dry powder will be collected and extraction will be done by the soxhlet method. Soxhlet method is also known as the hot continuous extraction method. In this method, we use the apparatus known as the Soxhlet apparatus. This apparatus consists of RBF (Round bottom flask), extractor tube (contain thimble made of strong filter paper), connecting adapter and condenser. The scholar will load the powder drug in the thimble packet then pack it with a pad of cotton because the drug can't overflow. Then fill the RBF with menstruum will attach the 4 parts. Then heat the RBF with a heat provider which produces vapour and condense it by the condenser, drops in the powder and wet it. By this continuous process, the extract will be collected in the RBF. This is a slow and continuous process. 


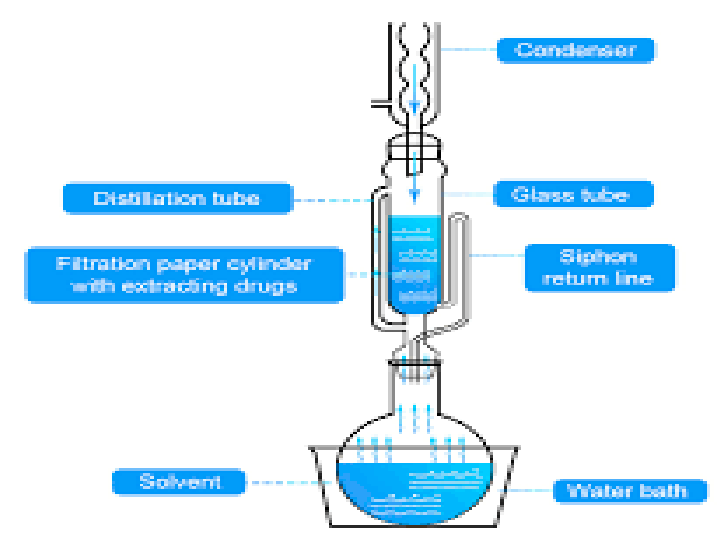

Every polymer has high molecular weight and is widely used in pharmaceutical systems as suspending, adjuvants, adhesives, emulsifying agents and coating material for controlled and site-specific drug delivery systems. Poloxamers are interesting copolymers as nanocarriers having amphiphilic characters. Due to large solubility differences between hydrophobic and hydrophilic moieties, in an aqueous medium, they can self-assemble into polymeric micelles consist of water-insoluble cores and water-soluble shells. The scholar will use this polymer for preparing PVK thermo-sensitive vaginal gel. Due to the weak mechanical strength of
Poloxamer, it causes rapid erosion in the vaginal canal. To overcome this difficulty and increase the contact time in the vaginal surface it will mix with the gel with mucoadhesive carbopol (C-974 or C980). By adding the polymer poloxamer, carbopols and PVK extract the Thermo-sensitive vaginal gel will be prepared. The process will be discussed after preparation.

\section{DISCUSSION}

The thermo-sensitive gel is in the liquid form at room temperature $\left(20-25^{\circ} \mathrm{c}\right)$ and undergoes gelation when in contact with body fluid $\left(35-37^{\circ} \mathrm{c}\right)$. Poloxamer a block copolymer made of polyoxyethylene (PEO) and polyoxypropylene (PPO) is known for its excellent compatibility, high solubility with other chemicals and drugs. At low temperatures, both PEO and PPO blocks of the poloxamer are soluble in water. As a result, the PEO-PPO-PEO chain exists as unimers and form cage-like structures in water and exist as a liquid. At higher temperatures, the cage-like structures are broken and the hydrophobic PPO blocks are exposed. Therefore they can associate to form micelles and thus form gels at higher temperatures.

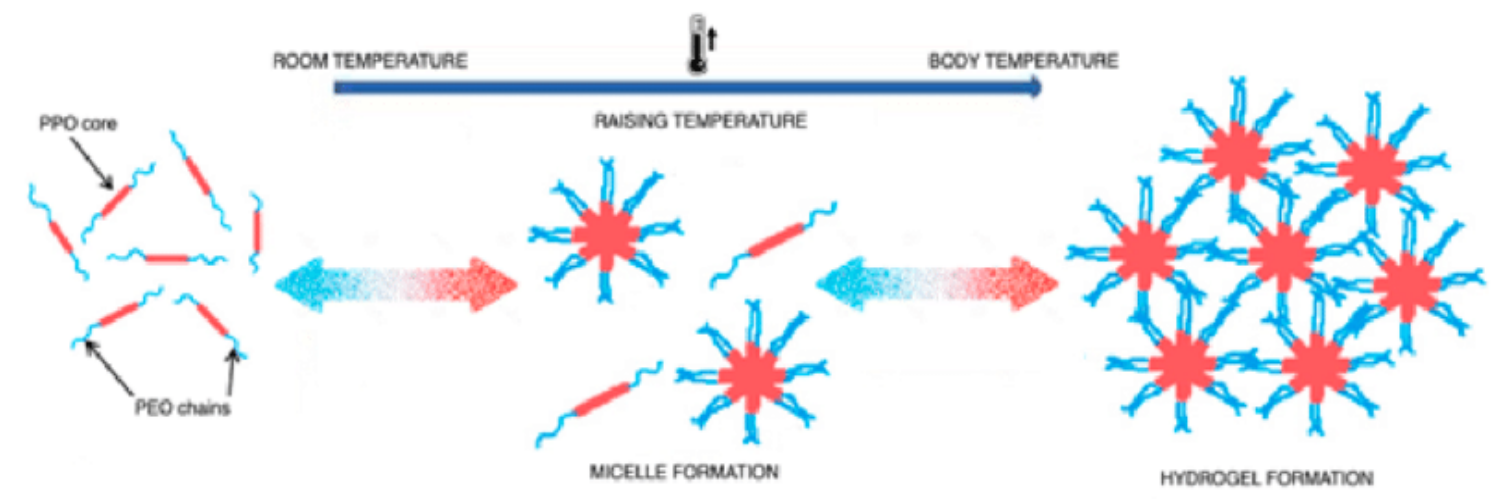

\section{CONCLUSION}

For Global acceptance, we will need to prepare the new doses form of Ayurvedic formulation. The thermo-sensitive vaginal gel of PVK extract is an advanced doses form. It is easy to apply at home. It is liquid at room temperature so the accurate measurement of the dose will be taken in a syringe and push it just in the vaginal opening. There is the 
least chance of infection. Because of its sustained release, it will be applied once a day.

\section{REFERENCES}

1. Danilo Antonini, Daisy Machado, Adriana Melo, “ Preparation of Thermosensitive Gel for controlled Release of Levofloxacin and Their Application in the Treatment of Multidrug-Resistant Bacteria" $25^{\text {th }}$ July 2016

2. B. Sri Devi, N. Swarnalata, "Prevalence of RTI/STI among reproductive-age women (15-49 years) in urban slums of Tirupati town, Andhra Pradesh, Health and Population- Perspectives and Issues 30 (1) 5670,2007

3. Joshi Jayashree, Vaidya Rama, Jagtap Sujata, Rege Vanita, Meheta Dilip, Vanage Geeta, "CCRAS MONOGRAPH"

4. Joshi Jayashree, Vaidya Rama, Jagtap Sujata, Rege Vanita, Meheta Dilip, Vanage Geeta, "CCRAS MONOGRAPH"

5. Joshi Jayashree, Vaidya Rama, Jagtap Sujata, Rege Vanita, Meheta Dilip, Vanage Geeta, "CCRAS MONOGRAPH"

6. Sanjeevani S. Deshkar, Arun T. Patil, Sushilkumar S. Poddar "Development of Thermosensitive gel of Fluconazole for vaginal Candidiasis" Int J Pharm Sci, Vol.8, Issue 1, 391-398, Original Article.

7. K.T Chung et al, Crit Rev food sci Natr 1989 "Tanin in human Health a review".

8. Aditya Ganeshpukar and Ajay K Saluja "The pharmacological potential of Rutin".

9. Paulrayen. Antonisary et al, J pharm Pharmacol, 2011 Aug "Anti-inflammatory Analgesic and Antipyretic effects of friedelin isolated from Azima tetracantha Lam in mouse and Rat"

10. Herve Martial poumale poumale, Victor kuete, in medicinal plant Research in Africa,2013 "Coumarin and Related compounds from the medicinal plant of Africa".

11. Navpreet Kaur, Jasmine Chaudhary, Akash Jain and Lalit kishore "Stigmasterol; A comprehensive Review" IJPSR.

12. "Lupeol, A Novel Anti-inflammatory and anti-cancer dietary Tritenpene", Mohammad Sallen.

13. Muktar B, Bello, I.A, Lallao, MS "Isolation, characterization and antimicrobial study of Lupeol acetate from the root bark of Ficus sycomorus, Linn, JASEM ISSN 1119-8362 Vol 22(7) 1129-1133, 2018.
14. Kiran Sharma, Rasheeduz Zafer, " Occurrence of taraxerol and taraxasterol in medicinal plant" PHCOG REV 5:5- 2015.

15. Su- Jin Kim, Won-Seok Chung, Sung-Soo Kim, Seong-Gyu Ko, Jae- Young Um."Anti-inflammatory Effect of Oldenlandia diffusa and its Constituent, Hentriacontane, through Suppression of Caspase-1 Activation in Mouse Peritoneal Macrophase" phytotherapy Research.25(10): 1537-46 October 2011

16. Jacqueline Fariha Shimizu, Caroline Sprengel Lima and Ana Carolina Gomes Jardim "Flavonoids from ptenogyne nitens inhibit Hepatitis-C virus entry", Scientific Reports December 2017.

17. Anand A, Zuarwar.Subhash L, Bodhankar, “ Polyphenols in chronic diseases and their mechanism of action-2014

18. Rahul chulet, Mahesh Jhalharia, Pankaj Pradhan, Sarwari Sharma," Analgesic and Antipyretic activity of Albizzia Lebbeck “ Pharmacology online,3:737749(2010).

\section{Source of Support: Nil Conflict of Interest: None Declared}

How to cite this URL: Kirtidhara Behera et al: New Dosage Form In Ayurveda- Thermo-Sensitive Vaginal Gel Of PVK Extract. International Ayurvedic Medical Journal \{online\} $2021 \quad$ cited August 2021\} Available from: http://www.iamj.in/posts/images/upload/1754_1758.pdf 